\title{
Study of the deformation characteristics for red clay under
}

\section{drying-wetting cycles}

\author{
Kaisheng Chen ${ }^{1 . \mathrm{a}^{*}}$, Ronghua Zhu ${ }^{1 . b}$ \\ ${ }^{1}$ School of Civil Engineering, Guizhou University Guizhou Guiyang China \\ achen_kaisheng@163.com, ${ }^{b} 1412181607 @ q q . c o m$
}

Keywords: dry wet cycle; red clay; swelling shrinkage deformation;crack characteristic

Abstract: Because of the special engineering properties of red clay with high water content, high plasticity, high porosity and other special engineering properties, especially the water loss shrinkage of the subgrade surface has been cracked, which makes the subgrade produce a number of diseases. Paper took the red clay subgrade in Liupanshui Express Ring as the research object, then did dry wet circulation experiment on red clay, measured the swelling shrinkage deformation and fracture characteristics of red clay, reveals red clay swelling shrinkage deformation and crack evolution under the condition of dry wet circulation.

\section{Foreword}

Because of the special engineering properties of red clay with high water content, high plasticity, high porosity and other special engineering properties, along with the continuity of highway operation time, the subgrade pavement has a disease. Such as Guiyang Bijie line, Guiyang Bijie line and so on, there are a lot of rut. Furthermore, a large number of pavement cracks were also found in the survey, crack size, crack shape is irregular, the most serious cracks are caused by the vertical subsidence, the length of the road surface subsidence is up to a hundred meters, which is mainly due to the roadbed subsidence. And if the roads which has built in the red clay area outside the province, many areas have encountered problems of different degrees of red clay. Such as 107 National Highway at the Moyang section in Hunan, the prevalence of semi rigid base, surface layer and cement concrete pavement cracking, broken plate and mud pumping and other early stage disease are widespread. When the road of the Moyang to Yizhang period among Beijing Zhuhai Expressway were building, the red clay embankment had been widely used near the Yizhang, causing serious embankment surface crack and net crack, crack unequal block sizes, the widest reach $5-6 \mathrm{~cm}$, depth can reach $26 \mathrm{~cm}$. The fundamental reason which brings about the subgrade pavement cracking is that the red clay losses water under the dry wet cycles. Therefore, the research on the deformation of red clay under the influence of wet and dry cycles has certain practical significance to the highway construction in the red clay area.

\section{basic physical properties of red clay}

The soil samples were taken from the inner ring of Liupanshui express 3. The characteristics of soil materials are: brown red, wet, uniform, compact structure, small amount of insect hole and the existence of plant root holes, from the composition of the particles to the silty clay. According to

"Regulations for Highway Soil Engineering Test" ( JTG E40-2007), the basic physical parameters of the soil are shown in Table 1. 
Table 1 basic physical indexes of red clay

\begin{tabular}{|c|c|c|c|c|c|}
\hline \multirow{2}{*}{$\begin{array}{c}\text { According to } \\
\text { “ Regulations for } \\
\text { Highway Soil } \\
\text { Engineering Test” } \\
\text { ( JTG E40-2007) }\end{array}$} & $>0.075 \mathrm{~mm} / \%$ & \multicolumn{2}{|c|}{$0.075 \sim 0.002 \mathrm{~mm} / \%$} & \multicolumn{2}{|c|}{$<0.002 \mathrm{~mm} / \%$} \\
\hline & 12.8 & \multicolumn{2}{|c|}{46.1} & \multicolumn{2}{|r|}{41.1} \\
\hline $\begin{array}{l}\text { The optimum water } \\
\text { content } / \%\end{array}$ & $\begin{array}{l}\text { the maximum } \\
\text { dry density of } \\
\mathrm{g} / \mathrm{cm}^{3}\end{array}$ & $\begin{array}{l}\text { plastic limit } \\
\qquad / \%\end{array}$ & $\begin{array}{l}\text { liquid } \\
\text { limit } / \%\end{array}$ & $\begin{array}{l}\text { coefficient } \\
\text { of } \\
\text { uniformity }\end{array}$ & $\begin{array}{l}\text { coefficient of } \\
\text { curvature }\end{array}$ \\
\hline 33.5 & 1.89 & 33.5 & 54 & 7.5 & 2.31 \\
\hline
\end{tabular}

\section{experiment scheme}

(1) sample preparation: samples prepared by heavy hammer compaction test,the compaction degree is $90 \%$, the initial water content is $23 \%, 33.5 \%, 54 \%$ respectively, the initial water content is, the diameter of sample is $150 \mathrm{~mm}$, the height is $120 \mathrm{~mm}$.

(2) set the needle: needle arranged on the level of the specimen surface and vertical direction, simultaneously measured the distance of the needle in the horizontal direction and the vertical direction after each dry wet cycle, in order to reflect the expansion and shrinkage deformation in the horizontal direction and the vertical direction.

(3) test method of wet and dry cycle: dry process: when the temperature is 105 degrees, placed the sample in an oven to dry (moisture content less than 1\%), wet process: use a syringe to add water to the initial water content after calculating the amount of water. The test method of wet and dry cycle is shown in figure 1.

(4) braised material: mixture sample into the moisture tank, feeding stew 24 hours.

(5) calculation and analysis: measure the sample height after dry cycle + wet cycle, the calculation of absolute swellingshrinkage and relative swellingshrinkagen. Meanwhile, measure the crack length, the number of maximum width and maximum.

(6) such a cycle is completed, and the following 5 cycles are completed by analogy. initial mołsture content

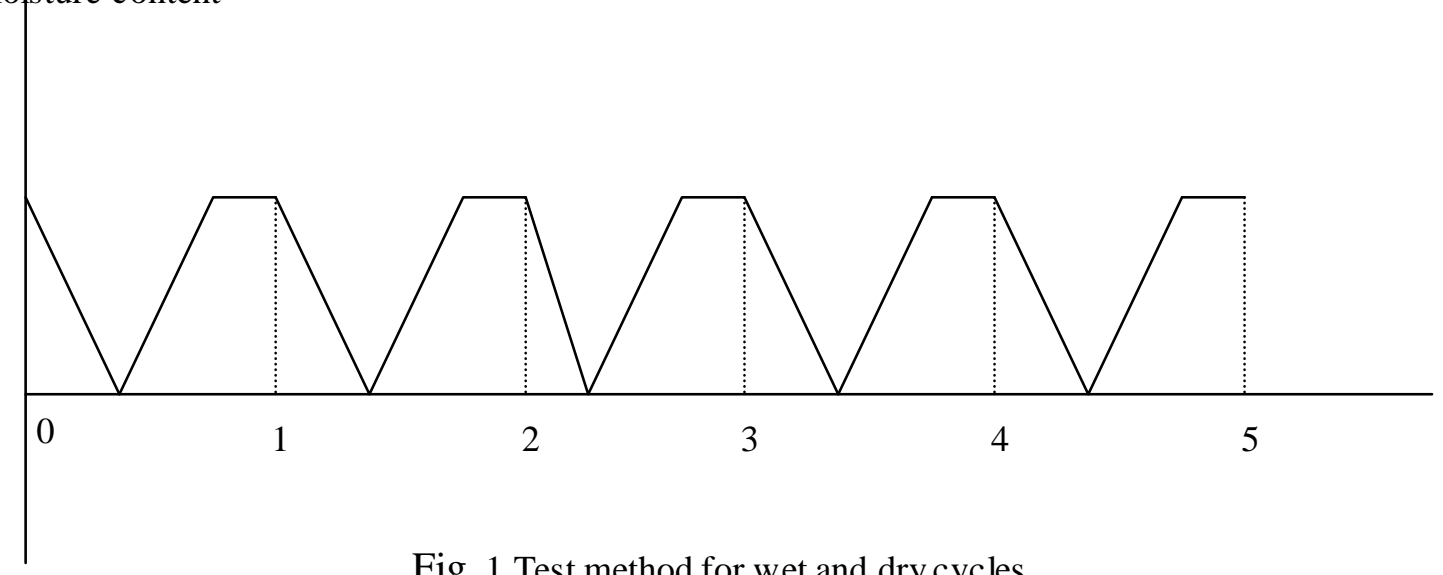

Fig. 1 Test method for wet and dry cycles

\section{test index}

In order to quantitatively analyze the swelling shrinkage deformation of expansive soil under wet dry cycle process, using the concept of absolute expansion and contraction and relative Swellingshrinkage to describe the sample expansion and contraction degree.

a. The absolute swellingshrinkage of the i time cycling test $a i$

$$
a i=\frac{z_{i}-z_{0}}{z_{0}} \times 100 \%
$$


Type : $z_{i}$ is the cycling test specimen height of the $\mathrm{i}$ time $(\mathrm{mm}) ; z_{0}$ is the initial specimen height or diameter $(\mathrm{mm}) . \quad a i<0$ expresses contraction; $a i>0$ means expansion. The absolute value of the value is larger, the greater expansion and shrinkage.

b. The relative swellingshrinkage of the i time cycling test $r i$

$$
r i=\frac{z_{i}-z_{i-1}}{z_{i-1}} \times 100 \%
$$

Type : $z_{i}$ is the height or diameter of test specimen in the $\mathrm{i}$ times cycling $(\mathrm{mm}) ; z_{i-1}$ is the height or diameter of test specimen $(\mathrm{mm})$ in the $\mathrm{i}-1$ times cycling. $r_{i}<0$ expresses contraction; $r_{i}>0$ means expansion. The greater the absolute value of the value, the greater the speed of the expansion and contraction.

\section{test results}

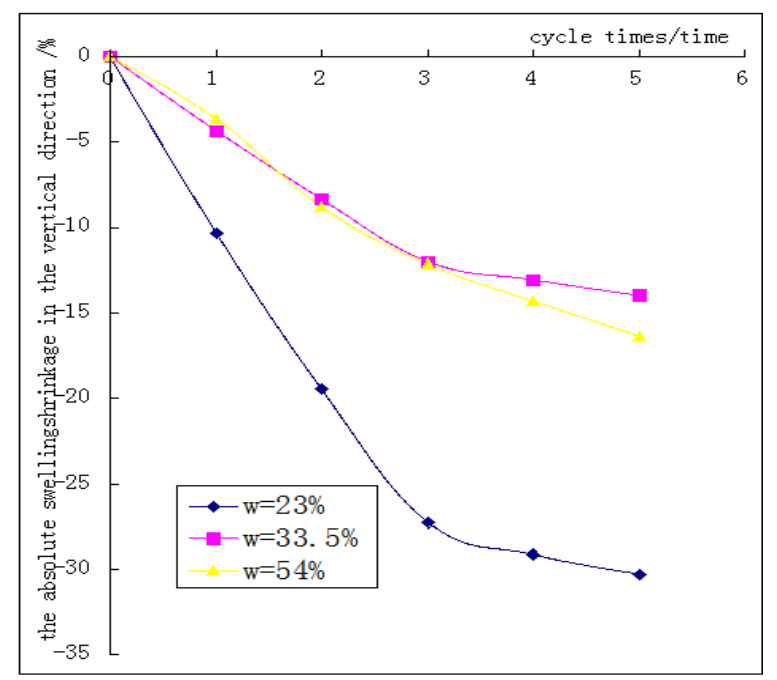

Fig. $2 \mathrm{~K}=90 \% \quad$ Relationship between the absolute swellingshrinkage in the vertical direction and the number of cycles

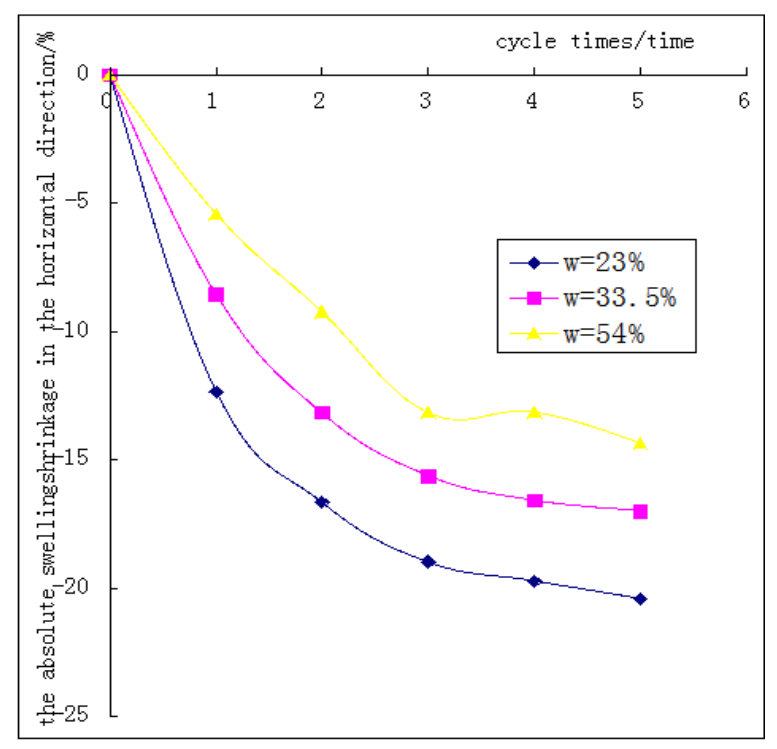

Fig.4 K=90\% Relationship between the absolute swellingshrinkage in the horizontal direction and cycles times

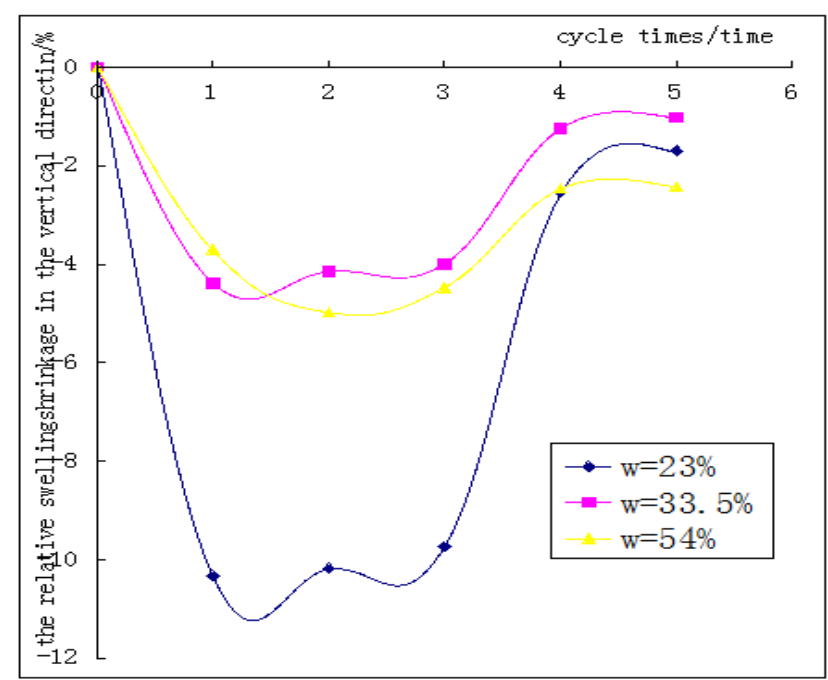

Fig.3 K=90\% Relationship between the relative swellingshrinkage in the vertical direction and cycles times

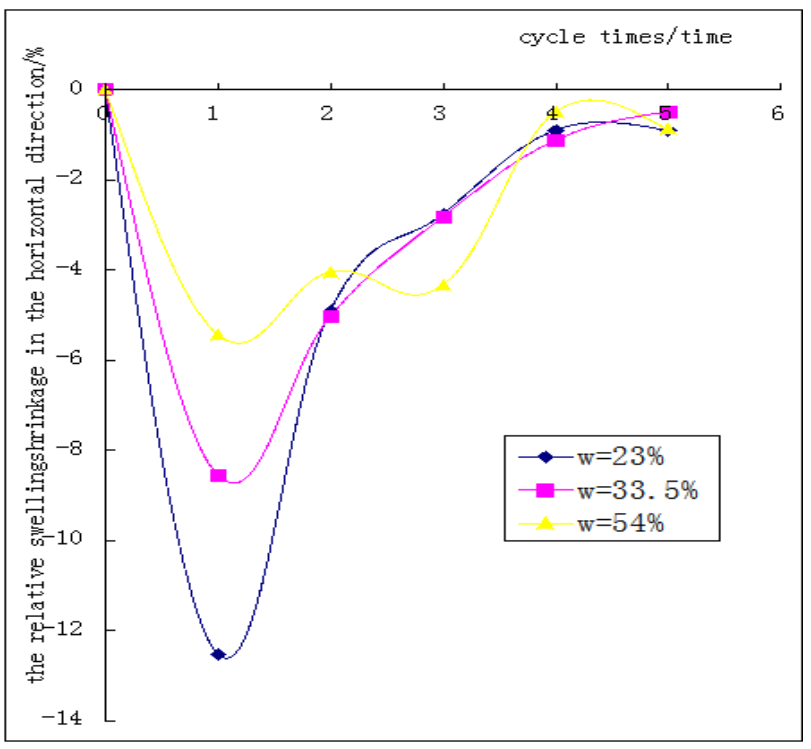

Fig.5 K=90\% Relationship between the relative swellingshrinkage in the horizontal direction and cycles times

From Figure 2 to figure 5 shows that, both in vertical direction and horizontal direction, 
absolute swellingshrinkage and relative swellingshrinkagen are negative, which indicates that the amount of shrinkage of the specimen is greater than the quantity of expansion so that specimen shows contraction, and the moisture content is smaller, the shrinkage is greater after the wet and dry cycle. The shrinkage of the sample shows three stages in total, the first stage: the curve is steeper, and before the first cycle, the shrinkage rate is increased; The second stage: the curve is flat, and from first cycles to third cycles, the shrinkage rate decreased slightly; The third stage: the curve is steeper, and from third cycles to fifth cycles, shrinkage rate decreased.

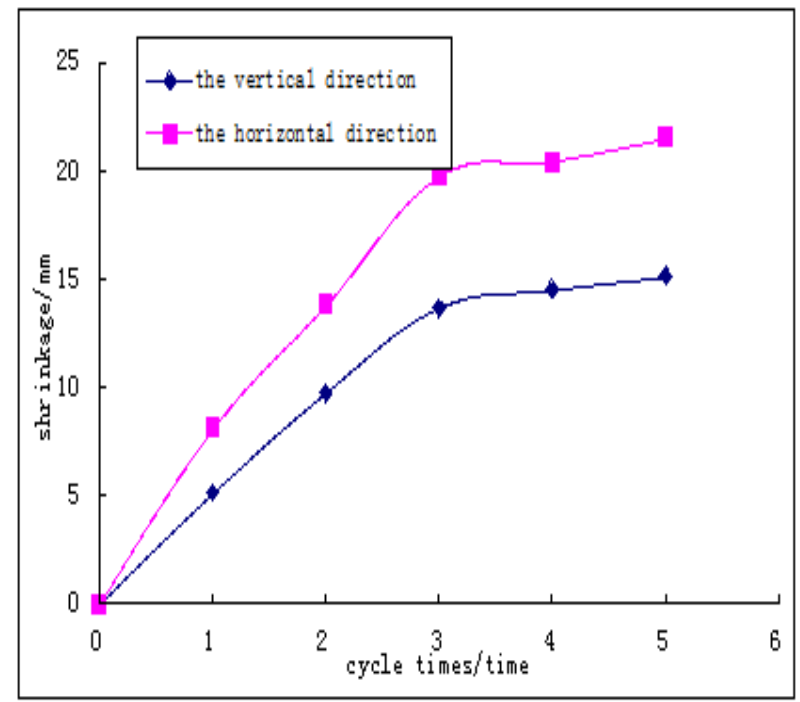

Fig.6 $\mathrm{K}=90 \%, \mathrm{w}=23 \% \quad$ Relationship between shrinkage and cycle count

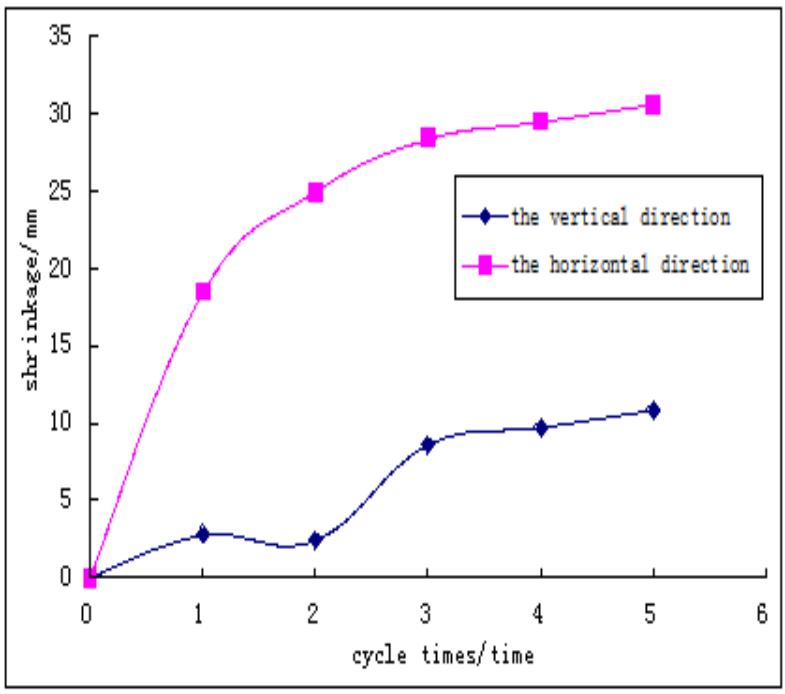

Fig. $8 \quad \mathrm{~K}=90 \%, \mathrm{w}=54 \%$ Relationship

between shrinkage and cycle count

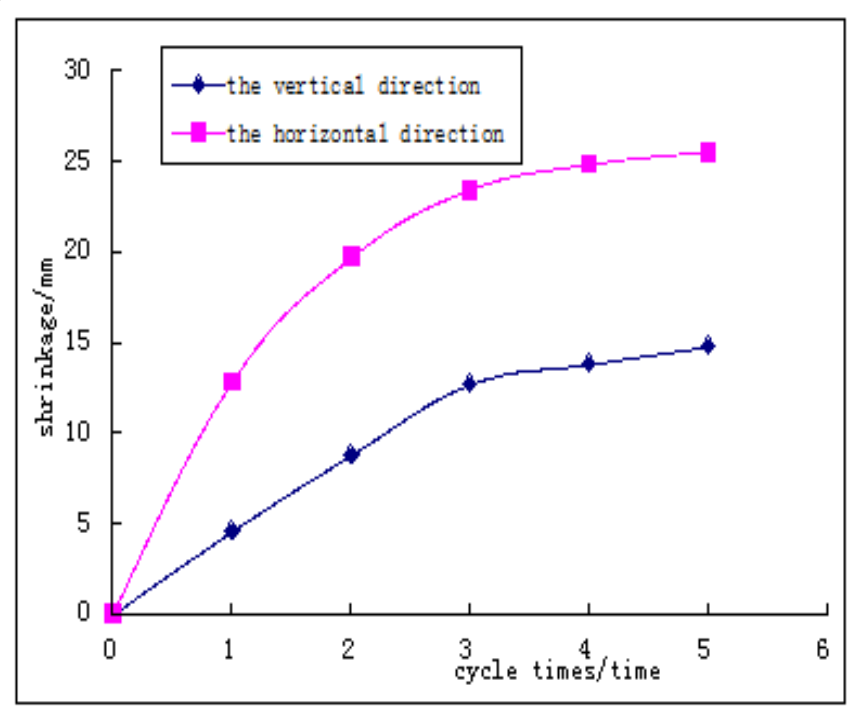

Fig.7 $\mathrm{K}=90 \%, \mathrm{w}=33.5 \%$ Relationship between shrinkage and cycle count

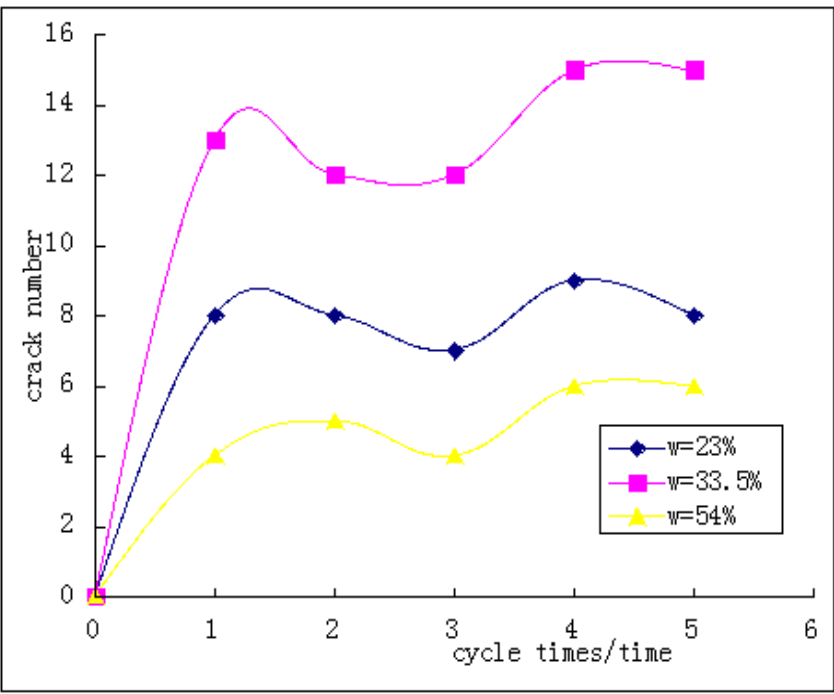

Fig.9 K=90\% The relationship between the number of cracks and cycle times

From figure 6 to figure 8, it is known that the amount of shrinkage in the horizontal direction is greater than that in the vertical direction, and the larger the water content is, the larger the difference between the horizontal and the vertical. 


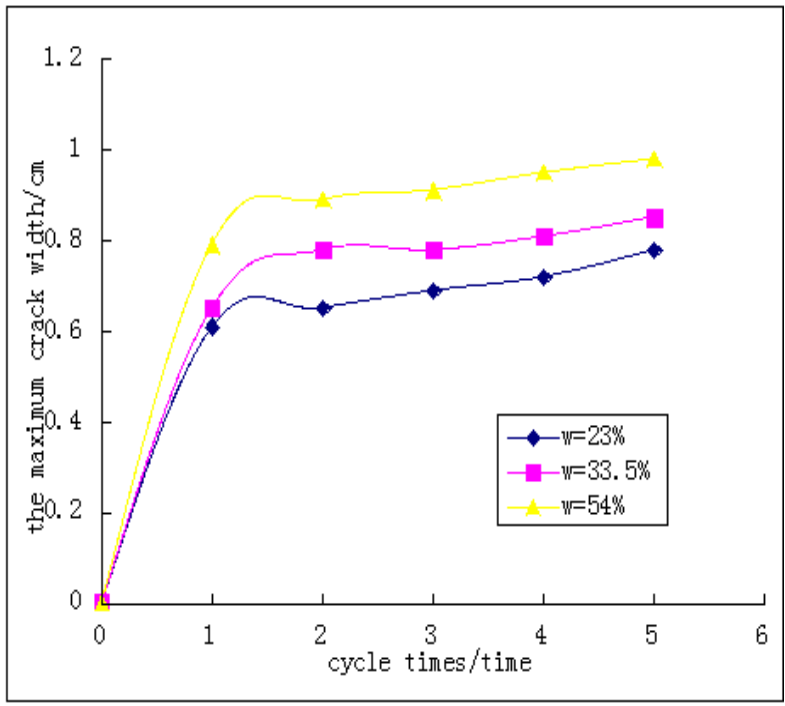

Fig.10 K=90\% The relationship between the maximum crack width and cycle times

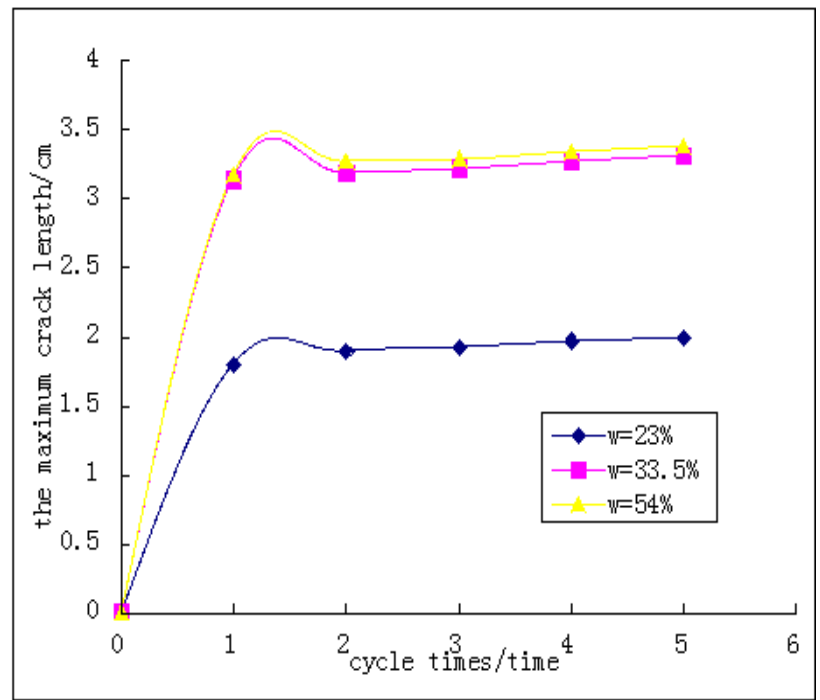

Fig.11 K=90\% The relationship between the maximum crack length and cycle times

From figure 9 to figure 11, we can see that with the increase of the number of cycles, the number of cracks, the maximum width and the maximum length of the first cycles increases rapidly, and then increases slowly, the curve is relatively flat. The experimental observation: first cycles, the soil samples appear a few big cracks, but no obvious micro cracks, which is due to the first cyc les of the original structure of the soil has been significantly damaged; second cycles, large cracks gradually reduced, and a small amount of micro cracks; third cycles, no major cracks, there are a lot of micro cracks. With the increase of dry wet cycles, the large fractures are decreased, micro fracture development, and more uniform distribution.

\section{conclusions}

(1) After wet and dry cycles, the shrinkage of the sample is greater than the expansion, and the sample shows a shrinkage. The shrinkage of the sample shows three stages in total, the first stage: the curve is steeper, and before the first cycle, the shrinkage rate is increased; The second stage: the curve is flat, and from first cycles to third cycles, the shrinkage rate decreased slightly; The third stage: the curve is steeper, and from third cycles to fifth cycles, shrinkage rate decreased.

(2) After wet and dry cycles, the shrinkage of the horizontal direction of the red clay is larger than that of the vertical direction.

(3) with the increase of the number of cycles, the number of cracks, the maximum width and the maximum length of the first cycles increased rapidly, and then increased slowly, the curve is relatively flat. The first cycles, soil samples appeared a few larger cracks, but no obvious micro cracks, is due to the first cycles of the original structure of the soil has been significantly damaged; second cycles, large cracks increasingly reduced, and a small amount of micro cracks; third cycles, no major cracks, there are a great many micro cracks. With the increase of dry wet cycles, the large fractures are decreased, micro fracture development, and more uniform distribution.

\section{Acknowledge ments}

This work was financially supported by National Natural Science Foundation of China(Approval number:51368010), Guizhou science and Technology Department—Guizhou University Foundation(Q iankehe Lh zi[2014]7663), Natural science research project of Guizhou Provincial Department of Education(Q ianjiaohe K Y zi[2015]488). 


\section{Reference}

[1] Regulations for Highway Soil Engineering Test (JTG E40-2007).

[2] Wu Shengjun. Experimental study on the law of water movement of red clay subgrade [D]. Master degree thesis of Changsha University of Science and Technology, 2010.4.

[3] Tao Wenping. Research on design and construction technology of red clay subgrade in South of China[D]. Master degree thesis of Changsha University of Science and Technology, 2010.4580-582

[4] Mu Xianjie, Zhang Xiaoping. Experimental study on mechanical properties of expansive soil under dry and wet conditions [J]. Rock and soil mechanics, 2008. (28) supplementary issue:580-582 [5] Yang Heping, Zhang Rui, Zheng Jianlong. Dry wet cycle deformation and strength of expansive soil under the loading condition. Journal of geotechnical engineering, 2006, 28 (11): 1936-1941 